\title{
Notas al estilo de Sarmiento
}

$\prod_{\text {odos los críticos de Sarmiento están de acuerdo en des- }}^{\text {tacar que no fue un creador puro, sino un autor de com- }}$ bate que siempre tomó la pluma para la defensa de una idea. También Sarmiento lo ha repetido a cada paso: "Soldado, con la pluma o la espada, combato para poder escribir, que escribir es pensar; escribo como medio y arma de combate, que combatir es realizar el pensamiento" (Prólogo a la Campaña del Ejército Grande, XIV, p. 68). ${ }^{1}$

Además, la grandeza de su obra de estadista ha atraído el análisis, el elogio o la polémica, en detrimento del estudio de sus condiciones de escritor. Sin embargo, ya se va formando una corriente de opinión ${ }^{2}$-Giusti, Onetti, Castro, Henríquez Ureña-que plantea la necesidad de considerar en

1 Todas las citas - excepto las del Facundo-están tomadas de las Obras de D. F. Sarmiento publicadas con los auspicios del Gobierno Argentino en Santiago de Chile y en Buenos Aires, desde 1885, en 52 volúmenes. Llevan indicado el título de la obra, el volumen en números romanos y la página. El Facundo - excepto la Carta-prólogo a la edición de 1851 - se cita por el excelente texto preparado y anotado por Raúl Moglia, Ediciones Peuser, Buenos Aires, 1955, con indicación de capítulo y página, aclarándose los casos en que la numeración del capítulo no coincide con la usada en las ediciones más corrientes, para facilitar la tarea del lector.

2 Roberto Grusti, "Sarmiento, escritor", Cursos y Conferencias, Buenos Aires, octubre-noviembre de 1938; Carlos María ONeTti, Cuatro clases sobre Sarminto escritor, Tucumán, 1939; AmÉrico CASTRo, "En torno al Facundo de Sarmiento", Sur, Buenos Aires, agosto de 1938; Pedro Henríquez Ureña, Literary Currents in Hispanic America, Harvard University Press, Cambridge, 1945. Anibal Ponce, Ricardo Rojas, Leopoldo Lugones, Ezequiel Martínez Estrada no están interesados preferentemente por su condición de escritor pero le dedican páginas a reces reveladoras. 
primer término la creación artística. Onetti se ha preguntado en qué consistía el que hombre tan poco atento aparentemente al modo de decir las cosas, y tan preocupado por las cosas mismas que debía decir, fuera un artista excepcional. Así, se muestra como enemigo del puro esteticismo, en la polémica que sostuvo con los discípulos chilenos de Bello al atacar los moldes vacíos y las imitaciones hueras :

Pero cambiad de estudios, y en lugar de ocuparos de las formas, de la pureza de las palabras, de lo redondeado de las frases, de lo que dijo Cervantes o Fray Luis de León, adquirid ideas de donde quiera que vengan, nutrid vuestro espíritu con las manifestaciones del pensamiento de los grandes luminares de la época; y cuando sintáis que vuestro pensamiento a su vez se despierta, echad miradas observadoras sobre vuestra patria, sobre el pueblo, las costumbres, las instituciones, las necesidades actuales, y en seguida escribid con amor, con corazón, lo que se os alcance, o que se os antoje, que eso será bueno en el fondo, aunque la forma sea incorrecta; será apasionado, aunque a veces sea inexacto; agradará al lector, aunque rabie Garcilaso; no se parecerá a lo de nadie; pero bueno o malo, será vuestro, nadie os lo disputará ("Segunda contestación a un quidam", I, p. 223).

Aquí encontramos una defensa de su prosa vital, prosa de luchador que se interesa más por la novedad y el empuje renovador de las ideas, que por la corrección y la fidelidad a los modelos. Una defensa del sentimiento y de la pasión, de lo espontáneo y lo instintivo que puede llegar a ser aún más enérgica, con la cual sigue juntamente las tendencias de su particular temperamento y los ideales de la escuela romántica que triunfa en su época. "He escrito, pues, lo que he escrito - dice con afirmación rotunda en el prólogo a los Viajes-porque no sabría cómo clasificarlo de otro modo, obedeciendo a instintos y a impulsos que vienen de adentro, y que a veces la razón misma no es parte a refrenar" (V, p. 9). Necesidad esencial y profunda que halla su justificación en sí propia por el ímpetu irrefrenable que le dio origen y por el solo hecho de existir.

En las formas que emplea Sarmiento para hablar de su labor de autor hay siempre un borbollear de vida ("el despilfarro de ideas y pensamientos que reclama" la pren- 
sa periódica, Recuerdos de provincia, III, p. 69; "por retocar obra tan informe, desapareciese su fisonomía primitiva, y la lozana y voluntariosa audacia de la mal disciplinada concepción", Carta-prólogo de la edición del $F a$ cundo de 1851, Obras, VII, p. 16) ; hay un insistir en el apresuramiento de la tarea ("fruto de la inspiración del momento"'..."ejecutada no bien era concebida, lejos del teatro de los sucesos, y con propósitos de acción inmediata y militante"... "páginas precipitadas", ibidem, p. 16) ; hay también un destacar la lucha y muchas veces el placer de la lucha. ${ }^{3}$

Sarmiento en persona parecería dar la razón a los que le juzgan un genio espontáneo y descuidado, hombre de acción más que creador consciente. Pero todo lo que acabamos de recordar no debe llevarnos a olvidar que fue un escritor nato, que sabía lo que quería hacer y cómo lo quería hacer, que era capaz de juzgar a los otros escritores y juzgarse a sí propio, y capaz de sentir en grado sumo el halago de la gloria literaria. En la crónica dedicada a $E l$ rey se divierte, de Víctor Hugo (II, p. 73) sentenciaba: "El autor que en su obra deja que el fondo domine y sofoque a la forma, es impotente; $y$ el que deja que la forma domine y sofoque al fondo, es charlatán." Aunque hoy no hablemos en términos de fondo y forma, resulta revelador un juicio de la labor literaria que es -en última instancia y por contraste- una definición de poderío intelectual, una afirmación del espíritu del hombre que cuando es un gran artista, se enseñorea de la materia (fondo o forma) de sus creaciones.

Esta y otras manifestaciones que luego veremos, nos impulsan a estudiar la prosa de Sarmiento desde un punto de vista estético, es decir, a destacar los medios expresivos que

3 Véase la "Primera polémica literaria", I, especialmente pp. 224-226. Es curioso cómo se jacta de su estrategia: "Pero ya que nos veíamos cogidos en la red, quisimos poner la cuestión en términos que removiese los ánimos, suscitase antipatías y aficiones a fin de que todos los que se interesan en esta materia prestasen atento oído a lo que se iba a decir por ambas partes, y no sucediese lo que de ordinario con los trabajos de la prensa periódica, que pasan de dia claro delante de nosotros como las aves nocturnas cruzan el cielo en el silencio de la noche, sin que nadie se fije en ellas" (p. 225); "grande fermentación ha causado nuestro artículo del 22 de mayo, y bueno fuera que no hubiéramos logrado nuestro intento cuando poníamos todos los medios de conseguirlo" (p. 226). 
eligió, quizá con mayor conciencia de lo que se cree, para trasmitirnos su mensaje. Por ahora nos limitaremos a algunos aspectos del Facundo, sin agotarlos.

\section{IMPORTANCIA DEL PLAN EN EL FACUNDO}

A primera vista llama la atención la importancia que da al plan de la obra, contra lo que se esperaría de un escritor tildado de improvisar. Consideremos el porqué de dicha actitud. El Facundo es un panfleto contra la tiranía de Rosas, pero juntamente es un intento de explicar el fenómeno del caudillismo por las especiales condiciones de la cultura de América - suelo, colonización española, vida pastoril en el desierto. Tiene el apasionamiento de la lucha y la intensidad de una demostración en que se echa mano de todos los medios, desde la estadística hasta la imprecación, para convencer de algo que se ve allí patente como la luz del día, pero que hay que introducir en las mentes reacias de los oyentes sea como fuere. La fuerza y la verdad de lo que dice no admiten dudas para Sarmiento:

...si un pobre narrador americano se presentase ante ellos con un libro, para mostrarles, como Dios muestra las cosas que llamamos evidentes, que se han prosternado ante un fantasma, que han contemporizado con una sombra impotente, que han acatado un montón de basura, llamando a la estupidez energía, a la ceguedad talento, virtud a la crápula, e intriga y diplomacia a los más groseros ardides (Carta-prólogo de la edición de 1851, Obras, II, p. 17).

Pero debe probar su verdad. Así acude a todos los resortes del hombre, y llama a su sensibilidad y a su intelecto con esa mezcla maravillosa de pasión y de raciocinio que hay en él mismo. Porque últimamente, lo que se propone es superar la pasión y orientar la acción buscando las razones del mal para encontrar con ellas la respuesta a los problemas de la patria.

Tiene para ello un plan intuido con claridad antes de redactar su libro ${ }^{4}$ e irá desenvolviéndolo en páginas y páginas

4 Pedro Henriquez Ureña dijo de sus libros: "They are solidly built; he wrote them in haste, but conceived their structure complete and harmonious from the start" (obra citada, p. 133). 
minuciosas. Sabe, sin embargo, que el lector es desatento, distraído, perezoso y no puede correr el riesgo de que no siga paso a paso la explicación que ha proyectado. ${ }^{5}$ Por eso parecería que se apodera de él desde los primeros capítulos y no 1c suelta. Por una parte excita su interés con un diálogo constante que no le deja desviar la atención, con preguntas, respuestas, exclamaciones, recursos que subrayan las opiniones, sacudimientos y virajes súbitos, respiros y sorpresas, pausas y nuevas arremetidas. Por otra parte, temiendo que se extravíe entre tantas digresiones y no mantenga el hilo de su razonamiento, le recuerda a cada paso el plan que lo guía para que al final quede claro el camino recorrido y pueda casi acabar con la fórmula tradicional: quod erat demostrandum.

En varios pasajes de la "Introducción" expone la novedad de las explicaciones que ha concebido a la arquitectura de la obra:

Hubiérase entonces explicado el misterio de la lucha obstinada que despedaza a aquella República; hubiéranse clasificado distintamente los elementos contrarios, invencibles, que se chocan; hubiéranse asignado su parte a la configuración del terreno y a los hábitos que ella engendra; su parte a las tradiciones españolas y a la conciencia nacional, inicua, plebeya, que han dejado la Inquisición y el absolutismo hispano; su parte a la influencia de las ideas opuestas que han trastornado el mundo político; su parte a la barbarie indígena; su parte a la civilización europea; su parte, en fin, a la democracia consagrada por la Revolución de 1810, a la igualdad, cuyo dogma ha penetrado hasta las capas inferiores de la sociedad (pp. 10-11).

...porque en Facundo Quiroga no veo un caudillo simplemente, sino una manifestación de la vida argentina tal como lo han hecho la colonización y las peculiaridades del terreno, a lo cual creo necesario consagrar una seria atención, porque sin esto, la vida y hechos de Facundo Quiroga son vulgaridades que no merecerían entrar sino episódicamente en el dominio de la Historia (p. 15).

$Y$ al final de esta introducción, en la que critica la biografía de Bolívar hecha con un enfoque europeo, resume su

5 Recuérdese el texto citado en la nota 3. 
Facundo fundado en circunstancias intrínsecamente americanas :

Razones de este género me han movido a dividir este precipitado trabajo en dos partes: la una, en que trazo el terreno, el paisaje, el teatro sobre que va a representarse la escena; la otra, en que aparece el personaje, con su traje, sus ideas, su sistema de obrar; de manera que la primera esté ya revelando a la segunda, sin necesidad de comentarios ni explicaciones (p. 16).

Quedan, pues, concretadas las causas del caudillismo en la carrera de un hombre típico cuyos antecedentes culturales se desarrollan en la primera parte para recoger en la segunda los resultados fatales de dichos modos de vida. Hasta aquí no advertimos más que el procedimiento usual en muchos autores: la presentación sintética del libro en el prólogo. ${ }^{6}$ Ya no es tan común que a través de toda la obra se refiera a ese plan concebido previamente. Sarmiento va recordando por qué le interesa la descripción del suelo. Puede indicarlo en larga digresión teórica sobre la dependencia del medio geográfico, las costumbres y el carácter de los habitantes:

Hay que hacer notar de paso un hecho que es muy explicativo de los fenómenos sociales de los pueblos. Los accidentes de la naturaleza producen costumbres y usos peculiares a estos accidentes, haciendo que donde estos accidentes se repiten vuelvan a encontrarse los mismos medios de parar a ellos, inventados por pueblos distintos (cap. II, p. 36).

$O$ en una frase certera y breve:

. .la pampa es un malísimo conductor para llevarla [la civilización] y distribuirla en las provincias, ya veremos lo que de aquí resulta (cap. I, p. 22).

También alude a cada momento a las influencias de la organización de la sociedad: ${ }^{7}$

6 Lo que no es tan común, tampoco, es el apóstrofe a la sombra de Facundo, al cual nos referiremos al final de este artículo. Para el modo de interpretar la historia en Sarmiento véanse Américo Castro, obra citada, y Tulio Halperín Donghi, "Facando y el historicismo romántico", La Nación, Buenos Aires, 23 de septiembre de 1956.

7 Véase también cap. IV, p. 60. 
Pero esta manera de numerar los pueblos argentinos no conduce a ninguno de los resultados sociales que voy solicitando. La clasificación que hace a mi objeto es la que resulta de los medios de vivir del pueblo de las campañas, que es lo que influye en su carácter y espíritu (cap. I, p. 26).

Constantemente se detiene a sintetizar el trabajo hecho y a proyectarlo en el futuro de la obra. Al finalizar un capítulo suele resumir el camino andado para que el oyente no lo pierda de vista y para subrayar ciertos aspectos fundamentales de su pensamiento que conviene recordar y tener siempre presentes en esa maraña. Después lo incita a continuar con él adelantando lo que le falta desarrollar y que cerrará el ciclo de la demostración. Futuro del libro ligado con el futuro de la patria, camino del lector que es su camino de hombre argentino o americano, de hombre ciego que no ve la realidad porque está inmerso en ella y que no adivina el porvenir de destrucción que le aguarda. Así acaba, por ejemplo, el capítulo III, dedicado a las formas de sociabilidad del gaucho, que precede al de la Revolución de $1810:^{8}$

Doy tanta importancia a estos pormenores porque ellos servirán a explicar todos nuestros fenómenos sociales y la revolución que se ha estado obrando en la República Argentina; revolución que está desfigurada por palabras del diccionario civil, que la disfrazan y ocultan, creando ideas erróneas; de la misma manera que los españoles, al desembarcar en América, daban un nombre europeo conocido a un animal nuevo que encontraban, ...La vida de los campos argentinos, tal como la he mostrado, no es un accidente vulgar: es un orden de cosas, un sistema de asociación característico, normal, único, a mi juicio, en el mundo, y él solo basta para explicar toda nuestra revolución. ... He indicado la asociación normal de la campaña, la desasociación, peor mil veces que la tribu nómade; he mostrado la asociación ficticia en la desocupación; la formación de las reputaciones gauchas; ...La revolución de 1810 llevó a todas partes el movimiento y el rumor de las armas. La vida pública que hasta entonces había faltado a esta asociación áraberromana entró en todas las ventas, $y$ el movimiento revolucionario trajo al fin la asociación bélica en la montonera provincial, hija legítima de la venta

3 Compárese cómo empieza el capítulo siguiente (p. 57), cómo acába el cap. II y comienza el III de la parte primera (pp. 47 y 49 ). Véase también cap. VII, p. 98 (parte segunda, cap. III en otras ediciones). 
y de la estancia, enemiga de la ciudad y del ejército patriota revolucionario. Desenvolviéndose los acontecimientos, veremos las montoneras provinciales con sus caudillos a la cabeza; en Facundo Quiroga últimamente, triunfante en todas partes la campaña sobre las ciudades y dominadas éstas en su espíritu, gobierno y civilización, formarse al fin el gobierno central, unitario, despótico del estanciero don Juan Manuel Rosas, que clava en la culta Buenos Aires el cuchillo del gaucho y destruye la obra de los siglos, la civilización, las leyes y la libertad (pp. 54-55).

Muerto Quiroga, discute con el lector la necesidad de continuar el libro, ${ }^{9}$ porque Facundo es sólo representante de un fenómeno histórico más vasto y ha sido elegido como protagonista por su misma tipicidad ${ }^{10} \mathrm{y}$ por las posibilidades literarias que ofrece su carácter ingenuo y primitivo. Pero no quedaría completa la requisitoria de la tiranía si no se prolongasen las consecuencias de la barbarie hasta juzgar el gobierno de Rosas, predecir su inevitable caída y vislumbrar la realización de los sueños de paz y progreso de los proscritos.

Por lo que con su muerte no queda terminada una serie de hechos que me he propuesto coordinar, y, para no dejarla trunca e incompleta, necesito continuar un poco más adelante en el camino que llevo para examinar los resultados que produce en la política interior de la República, hasta que el número de cadá-

9. En la segunda y tercera edición del Facundo, Sarmiento suprimió los dos capítulos finales por consejo de Valentín Alsina: "He suprimido la introducción, como inútil, y los dos capítulos últimos como ociosos hoy, recordando una indicación de usted en 1846 en Montevideo, en que me insinuaba que el libro estaba terminado en la muerte de Quiroga" (Carta-prólogo de la edición de 1851, Obras, VII, p. 17), pero los repuso en la cuarta edición en castellano de 1874 y así ha seguido imprimiéndose.

10 Para Quiroga como prototipo del caudillismo y la barbarie véanse entre otros pasajes: Introducción, p. 9 y cap. IX, p. 139 (parte segunda, cap. V en otras ediciones). Para el escritor que se muestra eligiendo dentro de los prototipos sus caracteres representativos: "Aquí termina la vida privada de Quiroga, de la que he omitido una larga serie de hechos que sólo pintan el mal carácter, la mala educación y los instintos feroces y sanguinarios de que estaba dotado. Sólo he hecho uso de aquellos que explican el carácter de la lucha, de aquellos que entran en proporciones distintas, pero formados de elementos análogos, en el tipo de los caudillos de las campañas que han logrado al fin sofocar la civilización de las ciudades, y que últimamente ha venido a completarse en Rosas...". (cap. V, f. 79; parte segunda, cap. I en otras ediciones). 
veres que cubren el sendero ya sea tan grande que me sea forzoso detenerme hasta esperar que el tiempo y la intemperie los destruyan para que desembaracen la marcha (cap. XIV, pp. 197-198; tercera parte, cap. I en otras ediciones).

Sarmiento llega en este pasaje a expresar la saturación del crimen en un grado imposible de superar, por el paso insensible desde el ámbito del quehacer literario ("hechos que me he propuesto coordinar") al ámbito de las realidades donde se presenta moviéndose entre cadáveres que impiden la marcha y que sólo el ciclo de las fuerzas naturales ("el tiempo y la intemperie") borrarán.

Durante toda la obra marcha acompañado por el lector. A menudo se interrumpe para justificar observaciones que parecerían inoportunas o pueriles: por qué sigue ese plan y no otro, por qué elige ciertos detalles que considera significativos ("No sin objeto hago esta enumeración trivial", cap. I, p. 27), por qué trata en tal momento formas de vida que juzga reveladoras y que luego se irán reproduciendo en el transcurso de la narración ("Aun podría añadir a estos tipos originales muchos otros igualmente curiosos, igualmente locales, si tuviesen, como los anteriores, la peculiaridad de revelar las costumbres nacionales... Andando esta historia, el lector va a descubrir por sí solo dónde se encuentran el rastreador, el baqueano, el gaucho malo y el cantor", cap. II, p. 47). También suele volverse hacia atrás y enlazar los personajes últimos con los prototipos de las primeras páginas patentizando la perfecta coherencia de su relato (La Madrid es "el cantor de que hablé en la primera parte”, cap. VIII, p. 112; segunda parte, cap. IV de otras ediciones. "Si el lector se acuerda de lo que he dicho del capataz de las carretas, adivinará el carácter, valor y fuerzas del Boyero", cap. XI, p. 151; segunda parte, cap. VII de otras ediciones).

Constantemente comenta el historiador la selección y ordenamiento ${ }^{11}$ que lleva a cabo entre los datos que la realidad le ofrece, ya eligiendo por razones estéticas ("Sacrifico la relación [de infamias] a la vanidad de autor, a la pretensión literaria. Diciendo más los cuadros saldrían recargados, inno-

11 Véase nota 10. 
bles, repulsivos", cap. VI, p. 95; segunda parte, cap. II de otras ediciones) ; ya desechando por razones éticas ; ya siguiendo criterios de agrupamiento que le inducen a sacrificar la cronología y a guiarse por el interés de lo que desea probar ("Como mi ánimo es sólo mostrar el nuevo orden de instituciones que suplantan a las que estamos copiando de la Europa, necesito acumular las principales, sin atender a las fechas", cap. XIV, p. 205; tercera parte, cap. I en otras ediciones). Así surge con nitidez una visión abarcadora de la obra toda, que calcula al desarrollar un pasaje lo que conviene tratar en él y lo que debe dejarse para capítulos posteriores:

No entraré en todos los detalles que requeriría este asunto ... La vida de Facundo Quiroga nos proporcionará ocasión de mostrarlo en toda su desnudez. Lo que por ahora necesito hacer notar es que, con el triunfo de estos caudillos, toda forma civil, aun en el estado en que las usaban los españoles, ha desaparecido totalmente en unas partes; en otras, de un modo parcial, pero caminando visiblemente a su destrucción (cap. IV, p. 61).

Digámoslo ya bien claramente. Lo importante no es que Sarmiento haya redactado su libro con una armazón consciente y calculada: muchos lo han hecho antes que él; aunque ya resulta curioso que se haya conducido de ese modo un autor del que se afirma que creó sin plan, al azar de lo que iba escribiendo clía a día mientras le arrancaban de las manos las cuartillas para llevarlas a la imprenta. Importa más que Sarmiento no se haya contentado con proceder así, y que haya recalcado también que procedía así y por qué procedía así. Lo singular es que haya sentido la necesidad de incorporar a su obra el comentario de cómo la realizaba.

Creemos que lo hizo por varios motivos. Sin duda vivió la originalidad de su intento ${ }^{12}$ —explicación de un fenómeno americano por circunstancias americanas-y quiso destacarlo con el orgullo del escritor consciente de su propio valer como

12 Era sin duda la idea de la Asociación de Mayo ("El caudillo es el hijo del desierto y el desierto es lo que hay que conquistar"), pero le pertenecía la gloria de haberla desarrollado y sus compañeros de generación lo reconocían. Sus vidas de Aldao y Quiroga son para Echevertía: "lo más completo y original que haya salido de la pluma de los jóvenes proscriptos argentinos" (Ojeada retrospectiva). 
una exaltación y defensa de su labor. Además, siendo el libro íntegro un diálogo con su pueblo, argentino, chileno, americano, y aun con los poderosos de Europa, necesita que la demostración quede nítidamente delineada para llegar a convencerlos. Por otra parte, justificar un detalle es no sólo integrarlo en el conjunto del alegato, sino subrayar indirectamente la importancia del tópico colocándolo en un primer plano. A Sarmiento lo guían, pues, en este comentario paralelo a la narración de su historia, dobles motivos estéticos y activos.

\section{RELACIONES DEL AUTOR, EL LECTOR Y LOS PERSONAJES}

La sensación extraordinaria de literatura viva, espontánea, jugosa, que produce el Facundo nace en buena parte de la imposibilidad de juzgarla desde afuera porque nos vemos arrebatados por el torbellino de esa realidad allí evocada. Su prosa se despliega en un doble juego de tensiones: Sarmiento-lector, Sarmiento-personajes, todos incorporados a la obra, todos metidos dentro de ella, dialogando, imprecando, desplazándose por la vasta geografía de la Argentina, borradas las fronteras de la obra literaria porque todo es vida -y algo mucho más terrible - todo es nuestra trágica vida de argentinos y americanos. Veamos el primero de estos tres elementos así incorporados: autor, lector, personajes.

A Sarmiento no le basta conformar enteramente el libro con su poderosa personalidad, tiene que manifestar en voz alta su opinión. Unas veces la razona con cierta amplitud:

Creo que el cargo [de vanidad nacional entre los argentinos] no es del todo infundado, y no me pesa de ello. i Ay del pueblo que no tiene fe en sí mismo! ¡Para ése no se han hecho las grandes cosas! ¿ Cuánto no habrá podido contribuir a la independencia de una parte de la América la arrogancia de estos gauchos argentinos que nada han visto bajo el sol mejor que ellos, ni el hombre sabio ni el poderoso? (cap. I., p. 32).

Otras intercala, simplemente, una exclamación o una breve 
frase que se le escapa ${ }^{13}$-mejor dicho, que deja estampada en la forma ingenua de la exclamación que se escapa-porque predomina en él una estética de lo espontáneo ${ }^{14}$ y libre que se traduce no sólo en la elección y en la valoración de los temas, sino también en el modo de narrar. Así se desahoga con un " Dios mío!" desesperado (Introducción, p. 12) cuando le dicen que es inútil luchar contra la fatalidad encarnada en Rosas, o con un irónico "iBendito sea Dios!" (ibidem) ante la ceguera y la estupidez con que Guizot trata los problemas americanos, o con un combativo “i Qué ilusión!" (cap. XV, p. 230; tercera parte, cap. II en otras ediciones) contra la astucia dominadora de Inglaterra.

Tampoco falta el comentario a su tarea de escritor y la manifestación del placer que le produce ("el carácter del protagonista de aquel sangriento drama hace demasiado a mi asunto para que me prive del placer de introducirlo", cap. XI, p. 157 ; segunda parte, cap. VII de otras ediciones), goce estético-vital que nace al encontrarse con un tipo americano que confirma su tesis y que tiene además su adhesión de artista que se recrea en lo natural.

Sarmiento tiene una forma apasionada de sentir las ideas y de transmitirlas a los demás con la fuerza del convencimiento de lo que se ha vivido, para que queden en las mentes ajenas con la misma tensión dominante que tuvieron en su creador. Pero vuelve a llamarnos la atención no tanto el que haya pensado apasionadamente y haya querido luego actuar sobre el

13 Compárese con las interjecciones: “¡Cierto!", “QQué!”, “ ¡No!” de la Introducción, pp. 12, 13 y 14, o con las preguntas del final de la parte primera, cap. IV, p. 67.

14 Para su preferencia por las formas espontáneas en la vida y en la literatura o por los contrastes de refinamiento y primitivismo, que desarrollaremos en estudio aparte, véanse: cap. XIV, p. 197 (parte tercera, cap. I en otras ediciones); Introducción, p. 9; cap. V, p. 80 (parte segunda, cap. I en otras ediciones); cap. VIII, p. 112 (parte segunda, cap. IV en otras ediciones). En un pasaje de sus Viajes se muestran vivamente estas preferencias literarias, traducidas a la vez en un lenguaje de lo natural: "Echeverría describiendo las escenas de la pampa, Maldonado imitando el llano lenguaje, lleno de imágenes campestres del cantor, iqué diablos! por qué no he de decirlo, yo, intentando describir en Quiroga la vida, los instintos del pastor argentino, $y$ Rugendas, pintando con verdad las costumbres americanas; he aquí los comienzos de aquella literatura fantástica, homérica, de la vida bárbara del gaucho..." (V. p. 61). 
lector para contagiarle su pasión, sino el que se valga de la exposición de su experiencia obsesiva para alcanzarlo. Entonces el efecto surge de desplegar ante nuestros ojos su propio proceso de pensamiento-pasión:

¿Dónde, pues, ha estudiado este hombre el plan de innovaciones que introduce en su gobierno...? Dios me perdone si me equivoco, pero esta idea me domina hace tiempo: en la estancia de ganados, en que ha pasado toda su vida, y en la Inquisición, en cuya tradición ha sido educado... Si esta explicación parece monstruosa y absurda, denme otra ... (cap. XIV, p. 207; parte tercera, cap. I en otras ediciones).

Así queda incorporado al relato Sarmiento autor, agonista de su obra, que la medita y la sufre al mismo tiempo con intensidad insostenible y se vuelca entero -persona y escritor- en el libro. Por último puede llegar a presentarse en la cima del sufrimiento y de la indignación rompiendo toda la disciplina mental que se ha impuesto para comprender el fenómeno del caudillismo por el ejercicio del intelecto:

iNo es posible mantener la tranquilidad de espíritu necesaria para investigar la verdad histórica, cuando se tropieza a cada paso con la idea de que ha podido engañarse a la América y a la Europa tanto tiempo con un sistema de asesinatos y crueldades tolerables tan sólo en Ashanty o Dahomay, en el interior de Africa! (cap. IV, p. 60).

Con su lenguaje conversacional, directo, se vuelca en la narración ("lo diré todo de una vez", cap. XIII, p. 177 o parte segunda, cap. IX en otras ediciones; "es cosa de nunca acabar" cap. XIV, p. 202 o parte tercera, cap. I en otras ediciones) avanza entre exclamaciones, preguntas, respuestas, y aun se vuelve sobre lo dicho y se corrige para realzar aun más la espontaneidad de la pluma ("concluyeron por llamarse federales y unitarios. Miento, que no concluye aún la fiesta: que a don Juan Manuel Rosas se le ha antojado...", cap. VII, p. 108 ; parte segunda, cap. III en otras ediciones).

Parecería que a Sarmiento no le bastan los cortes del hilo discursivo donde se asoma y nos cuenta qué siente, qué opina, cómo se desespera ante lo que va contando. Todavía tiene que 
realizar algo más: la incorporación dinámica de su persona a la aventura. En esta obra de tempo acelerado como de tromba que se despeña, Sarmiento, testigo y relator de los hechos, se presenta también en movimiento desplazándose materialmente en la vasta geografía de la república, saltando de un lugar a otro para asistir afiebrado al sucederse de los acontecimientos: "Me es preciso dejar a Buenos Aires para volver al fondo de las demás provincias a ver lo que en ellas se prepara. Una cosa debo notar de paso ..." (cap. IX, p. 130; parte segunda, cap. $\mathrm{V}$ en otras ediciones). $\mathrm{Y}$ la angustia por la tragedia que se desata se acentúa además porque, si bien los lectores conocen la historia conclusa, el autor la relata minuto a minuto con la ansiedad de quien la va viviendo en la incertidumbre y la amenaza de un futuro temible.

En estos desplazamientos característicos de su estilo, arrastra a los oyentes $\mathrm{y}$, fusionados el yo y el vosotros, ya somos todos testigos directos del horror, ya hemos roto la barrera que nos separa de la obra, ya hemos dejado nuestros cómodos asientos y nos movemos arrebatados por el mismo ímpetu: "Pero vamos a Atiles, donde se está preparando un ejército para ir a recobrar la reputación perdida en la Tablada..." (cap. X ,p. 140 ; parte segunda, cap. VI en otras ediciones).

Algún momento prefiere dar a los acontecimientos reales la solemnidad y el aparato de las representaciones trágicas, siguiendo una metáfora de larga tradición literaxia. ${ }^{15}$ Entonces no somos ya los testigos del hecho vivo trasladados al lugar del suceso para asistir anhelantes a algo incierto que, aunque lo suponemos terrible, no podemos prever pues cae en lo inseguro del porvenir. Ahora nos lleva de la mano y seremos los horrorizados espectadores de un drama prefijado que nos sobrecoge con su ejemplaridad: "Por la puerta que deja abierta el asesinato de Barranca Yaco entrará el lector conmigo en un teatro donde todavía no se ha terminado el drama sangriento" (cap. XIV, p. 198; parte tercera, cap. I en otras ediciones).

15 Para la historia del topos vida-representación teatral véase Ernst Robert Curtius, Europäische Literatur und Lateinisches Mittelalter. Indudablemente en Sarmiento, que muestra päeferencia por estas metáforas, la idea de la Divinidad ha sido sustituída por una concepción de influencias (suelo, formas de vida, herencia cultural) que determinan el camino seguido por el hombre. 
No quedan limitadas a esto sus relaciones con el oyente. Para mantenerlo alerta, le obligará a leer con conciencia sin resbalar sobre las frases y también a pensar por su parte y a colaborar con el autor: "No; lo que pide es lo que la frase expresa: tradiciones, costumbres, formas, garantías, leyes, culto, ideas, conciencia, vidas, haciendas, preocupaciones : sumad todo lo que tiene poder sobre la sociedad, y lo que resulte ${ }^{16}$ será la suma del Poder Público pedida" (ibidem). Pero no basta la colaboración intelectual. Al fin lo que se está contando nos atañe a todos, autor y lectores sumergidos en ese mar de sangre: así nos incorpora sin remedio al terror y a la humillación pasando insensiblemente del ellos al nosotros y al vosotros, del razonar o el imaginar al padecer en la propia carne:

La América entera se ha burlado de aquellas famosas fiestas de Buenos Aires y mirádolas como el colmo de la degradación de un pueblo; pero yo no veo en ellas sino un designio político, el más fecundo en resultados. ¿Cómo encarar en una república que no conoció reyes jamás la idea de la personalidad de gobierno? La cinta colorada es una materialización del terror que os acompaña a todas partes, en la calle, en el seno de la familia; es preciso pensar en ella al vestirse, al desnudarse, y las ideas se nos graban siempre por asociación... IImaginaos una ciudad culta, hombres y niños vestidos a la europea, uniformados dos años enteros con un ribete colorado en el sombrero! ¿Os parece ridículo? iNo! Nada hay ridículo cuando todos, sin excepción, participan de la extravagancia y, sobre todo, cuando el azote o las lavativas de ají están ahí para poneros serios como estatuas si os viene la tentación de reiros (cap. XIV, p. 203; parte tercera, cap. I en otras ediciones).

Nadie se escapa, ni aun los otros pueblos americanos que juzgan friamente desde su posición de hombres libres la barbarie argentina como los espectadores de un mundo torpe o risible. A ellos también los increpa y los arrastra con la misma amenaza: "iNo os riáis, pues, pueblos hispanoamericanos, al ver tanta degradación! ; Mirad que sois españoles, y la Inquisición educó así a la España! Esta enfermedad la traemos en

16 El subrayado es nuestro. Compárese cap. VIII, pp. 115 y 119 (parte segunda, cap. IV en otras ediciones). 
la sangre" 17 (cap. VIII, p. 117 ; parte segunda, cap. IV en otras ediciones).

\section{PREGUNTAS, RESPUESTAS Y EXCLAMACIONES}

La tensión Sarmiento-lector, el juego del yo y el tú o el vosotros, el estilo vital, tienen su expresión más característica en las sucesiones de preguntas, respuestas y exclamaciones. Ya vimos que el Facundo está pensado con una relación constante entre el autor y el público, y esa relación toma muy a menudo la forma del diálogo.

La pregunta puede ir puesta directamente en boca de los oyentes para manifestar el estupor ante acontecimientos que resultan incomprensibles o para poner objeciones al discurrir del autor. Esto le permite presentarlos como participando en la obra, y además le da pie para desarrollar combativamente y con mayor amplitud sus propios argumentos.

Tras las lecciones de humillación y sometimiento de Quiroga vienen las de Rosas que encarcela en tandas a los habitantes de Buenos Aires hasta que casi la ciudad entera pasa por las prisiones:

¿Por qué? ¿Qué habían hecho? ... ¿Qué habían dicho? ¡Imbéciles! ¿ no véis que se está disciplinando la ciudad? ... ¿No recordáis que Rosas decía a Quiroga que no era posible constituir la República porque no había costumbres? ¡Es que está acostumbrando a la ciudad a ser gobernada; él concluirá la obra, y en 1844 podrá presentar al mundo un pueblo que no tiene sino un pensamiento, una opinión, una voz, un entusiasmo sin límites por la persona y por la voluntad de Rosas! ;Ahore sí que se puede constituir una República! (cap. VI, p. 93; parte segunda, cap. II en otras ediciones).

A la pregunta ingenua del lector que aun no ha entendido el sistema del terror responde la exclamación brutal que lo trae a la realidad; y la explicación del autor - desarrollada a su vez en preguntas y admiraciones irónicas_ repite la fraseo-

17 Metáfora que entusiasmaría a Unamuno. Este lenguaje de lo que está metido en las entrañas es una de las características de nuestro autor. 
logía del tirano que puesta en boca de Sarmiento cobra su pleno sentido de sarcasmo y de tragedia.

Existe otro pasaje que elegimos entre mil, pero que no queremos dejar de citar, aunque incompletamente, porque constituye un verdadero bombardeo de interrogaciones. Primero, los argumentos contrarios del oyente en forma de preguntas repetidas, con ese "¡ Dios mío!" intercalado como grito de desesperación de quien quiere hablar porque está cargado de razones y el adversario no le deja. Después, las propias preguntas de Sarmiento, interrogaciones retóricas que son respuestas apasionadas y que cubren una página entera:

\begin{abstract}
¿Rosas, según esto, no es un hecho aislado, una aberración, una monstruosidad? Es, por el contrario, una manifestación social; es una fórmula de una manera de ser de un pueblo. ¿Para qué os obstináis en combatirlo, pues, si es fatal, forzoso, natural y lógico? ¿Dios mío! ipara qué lo combatís! ... i Acaso porque la empresa es ardua, es por eso absurda? \& Acaso porque el mal principio triunfa, se le ha de abandonar resignadamente el terreno?... (Introducción, p. 12).
\end{abstract}

En ciertas ocasiones Sarmiento interroga formulando él mismo los argumentos que el lector propondría como quien está pertrechado de respuestas para cualquier objeción que quieren hacerle y se adelanta a manifestarlas en nombre de los otros y las contesta rebatiéndolas (" Os parece esto mucha degradación? No; así son los pueblos; así es el hombre cuando se ha perdido toda conciencia del derecho, cuando la fuerza brutal se desencadena").$^{18}$

El propio autor se desdobla en dos personajes que dialogan con el objeto de presentar vívidamente el desarrollo de su pensamiento. Las conjeturas toman entonces las formas de la interrogación y la respuesta:

\title{
¿Ha querido [Inglaterra] poner su mano poderosa para
}

18 Pasaje de la primera edición, que fue suprimido en la cuarta. (Cito por Obras, VII, p. 165). La interrogación puede no llevar a veces la segunda persona del plural, sino una pasiva con se que indique en forma general lo que la opinión pública pensaría u objetaría: "¿Creeráse que tanta mediocridad es natural a una ciudad del interior? ¡No! Ahí está la tradición para probar lo contrario" (cap. IV, p. 65). 
que no se levante en el Sur de la América un Estado como el que ella engendró en el Norte? ¿Qué ilusión! Ese Estado se levantará, en despecho suyo, aunque sieguen sus retoños cada año, porque la grandeza del Estado está en la pampa pastora, en las producciones tropicales del Norte y en el gran sistema de ríos de navegación cuya aorta es el Plata (cap. XV, p. 230; parte tercera, cap. II en otras ediciones).

Y como los móviles de la conducta de Inglaterra favorable al tirano le tocan a lo vivo, su figura de luchador se yergue en un lenguaje de la voluntad y de la confianza: borra con una exclamación los planes de dominio, y afirma su fe con el contraste de la lucha constante para renacer de la nada ("aunque sieguen sus retoños cada año") y el ímpetu avasallador de las fuerzas naturales.

Este tipo de frases es tan característico de Sarmiento que no sólo aparece en los momentos dialécticos en que las argumentaciones diversas parecerían pedirlo, sino aun en los casos de la simple narración. Tal la historia de la cinta colorada: "Pero aun quedaba mucho por arreglar. ¿Llevaba uno la cinta negligentemente anudada? ivergazos!; era unitario. ¿Llevábala chica?, ivergazos! era unitario. ¿No la llevaba?, idegollado por contumaz!" (cap. VIII, p. 116; parte segunda, cap. IV en otras ediciones).

La pregunta, según vamos viendo, nunca es un verdadero interrogante - petición objetiva de que se despeje una incógnita-, es la manifestación de un auge de la fantasía o un escape de la emoción y casi siempre un modo de actuar en el oyente. Preguntas y exclamaciones subrayan los conceptos que en una forma neutra requerirían la frase enunciativa, a veces con irónica admonición ("¿No os decía que el terror produce resultados mayores que el patriotismo?", cap. XII, p. 171; parte segunda, cap. VIII, en otras ediciones), otras con una característica saliente de su prosa: el indicar una afirmación enemiga, retomarla, insistir en ella y darle con una nueva luz el verdadero y horrible sentido (" $¿$ No habéis oído la palabra salvaje, que anda revoloteando sobre nuestras cabezas? De eso se trata: de ser o no ser salvaje", Introducción, p. 12).

El capítulo final del Facundo es una profecía del futuro brillante de la Argentina y contiene el programa de civilización 
europea que soñaban los proscritos. Está construído en un vaivén de contrastes entre lo que Rosas es y lo que ellos serán. A cada mal de la tiranía se opone un bien en una dialéctica constante. Rosas, destruyendo, colabora ciegamente con la buena causa, por esa vaga creencia de Sarmiento en un orden histórico de compensaciones que acaba por hacer triunfar el progreso. Toda la fuerza voluntariosa de nuestro autor, toda su fe en el porvenir de los justos, está en esos párrafos en que se suceden preguntas tras preguntas, sintetizadoras de los horrores de la tiranía. A cada pregunta responde un "no importa", un "pues bien" que acepta el mal y lo anula deduciendo de él una futura forma de bienestar. Las páginas se continúan en violenta tensión de oposiciones, como si se tratase de una lucha y a cada ataque del enemigo aparecieran nuevos escuadrones de refuerzo y choque. Pero en un momento la pasión es tal que Sarmiento rompe el paralelismo de la construcción, se sale de sus casillas - es decir de su posición de juez y profeta- y pasando insensiblemente de la tercera a la segunda persona se vuelve directamente a increpar al tirano y a dialogar con su personaje aborrecido, nuevamente borradas las barreras entre el escribir y el vivir:

¿Ha encadenado la Prensa y puesto una mordaza al pensamiento para que no discuta los intereses de la patria, para que no se ilustre e instruya, para que no revele los crimenes horrendos que ha cometido y que nadie quiere creer a fuerza de ser espantosos, inauditos? ¡Insensato! ¿Qué es lo que has hecho? Los gritos que quieres ahogar cortando la garganta, para que por la herida se escape la voz y no lleguen a los labios, resuenan hoy por toda la redondez de la tierra ... El americano, el enemigo de los europeos, condenado a gritar en francés, en inglés y en castellano: "iMueran los extranjeros!" "iMueran los unitarios!" ¡Eh! ¡Eres tú, miserable, el que te sientes morir, y maldices en los idiomas de esos extranjeros, y por la Prensa, que es el arma de esos unitarios! ¿Qué Estado americano se ha visto condenado como Rosas a redactar en tres idiomas sus disculpas oficiales para responder a la Prensa de todas las naciones, americanas y europeas a un tiempo? Pero, ¿adónde llegarán tus diatribas infames, que el execrable lema “iMueran los salvajes, asquerosos, inmundos unitarios!" no esté revelando la mano sangrienta e inmoral que las escribe? (cap. XV, pp. 234-235; parte tercera, cap. II en otras ediciones). 
Así llegamos al último de los tres elementos - autor, lector, personaje_- que antes citamos. El personaje odiado (Quiroga o Rosas) que nunca fue por entero una figura literaria, es ahora un ser vivo y presente, porque si ya ha muerto, Sarmiento conjurará su cadáver y le insuflará el espíritu vivificador para luchar con él. No necesitamos transcribir la página magnífica y sobrecogedora que abre el libro porque todos la recuerdan. En este momento no le basta a Sarmiento la fe en sus condiciones de artista que sabe dar existencia literaria a un hombre desaparecido, tiene que presentar ante nuestros ojos como una realidad que se desenvuelve ese hecho estético, y traducir su obra de creador por el verbo en un milagro de carne y hueso que nos llene de estupor:

"iSombra terrible de Facundo, voy a evocarte...!"

ANa Marfa BarRenechea.

Universidad de Buenos Aires, Instituto de Filología 